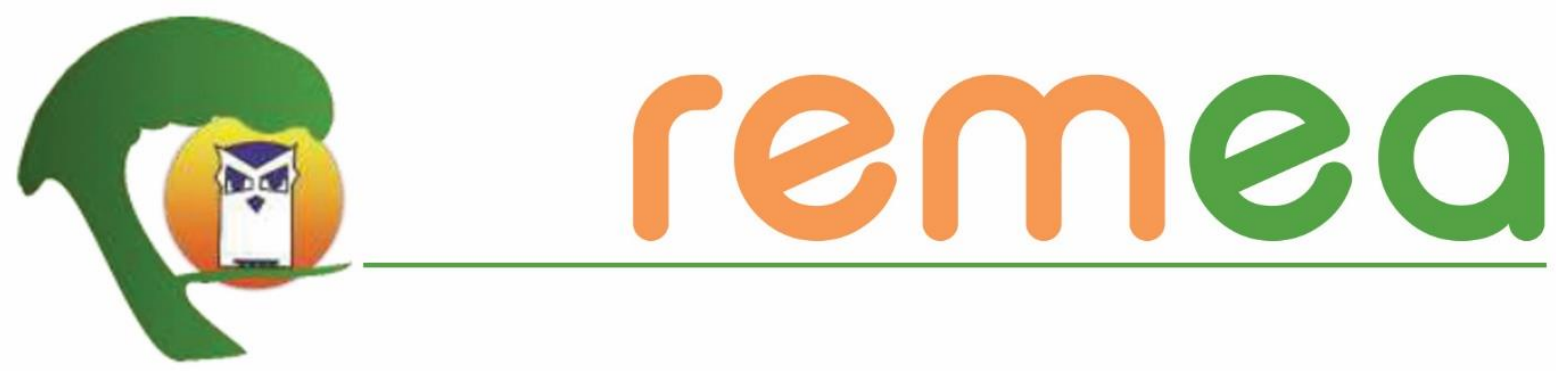

\title{
Contribuições e interconexões entre a complexidade e a dialética na pesquisa-ação em educação ambiental
}

\author{
Theóffillo da Silva Lopes ${ }^{1}$ \\ Universidade Federal da Paraíba \\ ORCID https://orcid.org/0000-0002-7775-4885 \\ Francisco José Pegado Abílio² \\ Universidade Federal da Paraíba \\ ORCID https://orcid.org/0000-0002-7217-4849
}

Resumo: Esse trabalho é fruto de inquietações epistemológicas acerca da pesquisa-ação e de pressupostos teóricos, epistemológicos e metodológicos da Teoria da Complexidade e da Dialética enquanto fomentadoras das discussões acerca da Educação Ambiental. Nesse sentido, tem como objetivo refletir sobre as contribuições e interconexões existentes entre a complexidade e a dialética na pesquisa-ação em educação ambiental. Desta forma, o trabalho caracteriza-se na reflexão da contribuição de categorias presentes na dialética para as discussões ambientais e o desenvolvimento de uma pesquisa-ação, tais como o trabalho, a totalidade e a práxis. E, ainda, a relação e diálogo destas com conceitos presentes na Complexidade, como a ecologia da ação, a unidade na diversidade (também presente na dialética), e a relação das partes com o todo. A partir disso, entender como essas contribuições e interconexões existentes contribuem para a construção de uma pesquisa alternativa, baseada na ação educativa, como ferramenta de transformação da realidade. Com isso, observa-se que a pesquisa-ação em educação ambiental, sob a ótica da complexidade e da dialética, se mostra como uma alternativa de emancipação dos participantes envolvidos no fenômeno, no sentido da compreensão das

\footnotetext{
${ }^{1}$ Doutorando em Educação PPGE/UFPB; Mestre em Desenvolvimento e Meio Ambiente PRODEMA/UFPB; Pedagogo da UFPB; e Professor de Educação Básica I na Prefeitura Municipal de João Pessoa-PB. João Pessoa/Paraíba. E-mail: theoffillo@outlook.com .

2 Professor Titular do Departamento de Metodologia da Educação, do Centro de Educação da Universidade Federal da Paraíba (UFPB). Bacharel em Ciências Biológicas pela UFPB (1994), Licenciado em Ciências Biológicas pela UFPB (2001), Mestre em Ciências Biológicas (Zoologia) pela UFPB (1997), Doutor em Ciências pela Universidade Federal de São Carlos (UFSCAR) (2002) e Pós-Doutor em Educação (Educação Ambiental) pela Universidade Federal de Mato Grosso (UFMT - 2011) sob a supervisão da Profa. Dra. Michèle Sato. João Pessoa/Paraíba. E-mail: chicopegado@yahoo.com.br.
} 
ideologias presentes nos discursos educacionais e ambientais, de sua superação, e da construção de uma sociedade ambientalmente consciente.

Palavras-chave: Complexidade, Dialética, Pesquisa-Ação em Educação Ambiental.

\title{
Contribuciones y interconexiones entre complejidad y dialéctica en investigación acción en educación ambiental
}

Resumen: Este trabajo es el resultado de inquietudes epistemológicas sobre la investigación-acción y los supuestos teóricos, epistemológicos y metodológicos de la Teoría de la Complejidad y la Dialéctica como impulsoras de discusiones sobre Educación Ambiental. En este sentido, pretende reflexionar sobre los aportes e interconexiones entre complejidad y dialéctica en la investigación-acción en educación ambiental. De esta manera, el trabajo se caracteriza por reflejar el aporte de categorías presentes en la dialéctica a las discusiones ambientales y al desarrollo de la investigación acción, como el trabajo, la totalidad y la praxis. Y, sin embargo, su relación y diálogo con conceptos presentes en la Complejidad, como la ecología de la acción, la unidad en la diversidad (también presente en la dialéctica), y la relación de las partes con el todo. A partir de ello, comprender cómo estos aportes e interconexiones existentes contribuyen a la construcción de una investigación alternativa, basada en la acción educativa, como herramienta para transformar la realidad. Así, se observa que la investigación-acción en educación ambiental, desde la perspectiva de la complejidad y dialéctica, se muestra como una alternativa para la emancipación de los participantes involucrados en el fenómeno, en el sentido de comprender las ideologías presentes en los discursos educativos y ambientales, superarlo y construir una sociedad con conciencia ambiental.

Palabras-clave: Complejidad, Dialéctica, Investigación Acción en Educación Ambiental.

\section{Contributions and interconnections between complexity and dialetics in action research in environmental education}

\begin{abstract}
This work is the result of epistemological concerns about action research and theoretical, epistemological and methodological assumptions of the Theory of Complexity and Dialectics as promoters of discussions about Environmental Education. In this sense, it aims to reflect on the contributions and interconnections between complexity and dialectics in action research in environmental education. In this way, the work is characterized by reflecting the contribution of categories present in the dialectic to environmental discussions and the development of action research, such as work, totality and praxis. And yet their relationship and dialogue with concepts present in Complexity, such as the ecology of action, unity in diversity (also present in dialectics), and the relationship of the parts with the whole. From this, understand how these existing contributions and interconnections contribute to the construction of an alternative research, based on educational action, as a tool for transforming reality. Thus, it is observed that action research in environmental education, from the perspective of complexity and dialectics, shows itself as an alternative for the emancipation of the participants involved in the phenomenon, in the sense of understanding the ideologies present in educational and environmental discourses, overcoming it, and building an environmentally conscious society.
\end{abstract}

Keywords: Complexity, Dialetics, Action Research in Environmental Education.

\section{Introdução}

Esse trabalho é fruto de inquietações epistemológicas acerca da pesquisa-ação e de pressupostos teóricos da Teoria da Complexidade e da Dialética enquanto fomentadoras das

Revista Eletrônica do Mestrado em Educação Ambiental Programa de Pós-Graduação em Educação Ambiental - FURG v. 38, n. 1, p.95-112, jan./abr. 2021. E-ISSN: 1517-1256 
discussões acerca da Educação Ambiental. Nesse sentido, tem como objetivo refletir sobre as contribuições e interconexões existentes entre a complexidade e a dialética na pesquisaação em educação ambiental.

Epistemologicamente, a pesquisa-ação enquanto método de pesquisa que se norteia na ação, com objetivo de transformação, está muito próxima da dialética, uma vez que se propõe a superar o caráter técnico-instrumental da pesquisa para assumir uma posição de não neutralidade da ciência e de mudanças que gerem emancipação em todos os sujeitos participantes da pesquisa.

Da mesma forma, enquanto método que se imbui da ação tomando como fundamento a compreensão do princípio da incerteza (MORIN, 2015), e que está aberto ao diálogo com o meio e os saberes existentes na pesquisa, em uma ecologia da ação, a pesquisa-ação apresenta abertura para o diálogo com a complexidade existente nas relações, nos processos e na totalidade.

Essas características podem ser observadas tanto nos pressupostos epistemológicos, gnosiológicos e ontológicos da pesquisa-ação, quanto nas categorias que permeiam este tipo de pesquisa. No que concerne à pesquisa-ação em educação ambiental, as normas e parâmetros estabelecidos à essa última ampliam as possibilidades de diálogos existentes no planejamento e execução da pesquisa.

Enquanto princípio epistemológico, apontado por Thiollent (2011), o objetivo da pesquisa-ação não é a investigação de pessoas, mas, dos problemas que perpassam diferentes naturezas, encontrados na situação social que essas pessoas vivem. Isso requer da pesquisa, e que isso esteja claro ao pesquisador, que a mesma tem como finalidade, se não resolver o problema encontrado, ao menos esclarecer os problemas para todos os participantes envolvidos na pesquisa.

Essa abertura epistemológica, amparada em uma orientação dialética, considera que as interpretações do fenômeno estudado, conforme esclarece Pimenta (2012), são realizadas no contexto da pesquisa, o que proporciona aos participantes desvelar as contradições existentes na dinâmica do movimento histórico e nas implicações dos processos existentes no fenômeno. 
A ação é um pressuposto indispensável da pesquisa que, não limitando-se a apenas isto, deve ter a ênfase da resolução de problemas, da tomada de consciência desses problemas e ainda da produção de conhecimento a partir desse processo. Nesse sentido, o conhecimento construído através da pesquisa-ação parte, não da subjetividade humana, mas da objetividade da existência concreta do mundo em transformação permanente, onde os participantes criam a própria consciência a partir do âmbito de uma consciência social que o envolve, antecede e condiciona (RICHARDSON, 2003).

Enquanto pressuposto gnosiológico da pesquisa-ação, o objeto de investigação não se caracteriza pelas pessoas, como já mencionado, mas está vinculado aos problemas que estas vivem e estão inseridas. Mesmo havendo uma pretensão clara por parte do pesquisador na realidade observada, existe uma ampla e explícita interação entre o mesmo e todos os participantes envolvidos na pesquisa.

Como uma prática social que visa transformar as condutas através da práxis, Franco (2012) observa que é primaz que haja tempo e espaço para que todos os participantes da pesquisa se apropriem dos problemas existentes, das mudanças ocorridas - enquanto finalidade da ação - e que cada um opere suas significações de mundo e das transformações alcançadas.

Para que essas significações estejam claras a todos os participantes, é importante que, ontologicamente explícito, seja apreendida a condição de ser social que se estabelece pelas práticas sociais e suas relações com o trabalho, o mundo e a natureza. Essa ontologia é ferramenta indispensável para proporcionar o entendimento sobre a realidade e a práxis necessária para suas mudanças.

Masson (2014) enfatiza que essa ontologia, além de centrada na práxis e nas relações estabelecidas a partir do trabalho, busca apreender o modo de ser e reproduzir-se do ser social na forma histórica capitalista. Esse modo de ser e reproduzir-se advindo do homem moderno e do capitalismo é exatamente um dos objetos centrais para a discussão da educação ambiental, enquanto práxis social que se propõe a gerar transformações individuais e coletivas na sociedade. 


\section{Pesquisa-ação em educação ambiental}

A educação ambiental, enquanto prática educativa envolvida numa práxis social que busca gerar mudanças de comportamentos individuais e coletivos, tem recebido atribuições políticas, gerenciais, técnicas, instrumentais e humanas para transformação da crise ecológica existente.

No entanto, essa crise "ecológica" existente tem se mostrado mais profunda que o aparente. Leff (2009) aponta que essa crise é da civilização, se perfazendo numa crise ética, política, ambiental, da modernidade, do capitalismo. Uma crise que advém da forma predadora que assume o trabalho humano e da relação desse trabalho com a natureza e entre a humanidade.

A historicidade e o conhecimento humano que podem ser apreendidos do resultado dessas relações entre a humanidade e da humanidade com a natureza são intermediadas pela educação. Nesse contexto, a educação ambiental assume um papel fundamental nas reflexões, problematização, transformação e emancipação dos sujeitos envolvidos em seus processos. Isso, quando garante como ponto de partida, uma interpretação crítica da realidade.

Obviamente, aponta Reigota (2014), que a educação ambiental por si só não poderá alcançar esses objetivos, porém, pode influir decisivamente para isso, quando forma cidadãos conscientes dos seus direitos e deveres. Conscientes da problemática ambiental e atuantes na sua comunidade.

Guimarães (2011) afirma que uma educação ambiental capaz de contribuir no enfrentamento da crise socioambiental que vivenciamos, é aquela que faz do ambiente educativo espaços de participação, onde a aprendizagem se dá em um processo de construção de conhecimentos vivenciais, que experiencie ações que tenham a intencionalidade como uma ação política de intervir na realidade transformando-a.

Como finalidade de transformação do que está posto, a educação ambiental abre espaço para pesquisas que tenham como objetivo ações para mudanças, de maneira que 
seus pressupostos se perpassem de forma dialógica, estabelecendo um canal de comunicação, execução e aproveitamento eficaz.

Esse processo educativo, que assume seu caráter político e intencional, não pode encontrar espaço em pesquisas convencionais que são regidas no mito da neutralidade, mas em metodologias que tenham a abertura epistemológica necessária para assumir o aspecto subjetivo da ciência. Nesse âmbito, a pesquisa-ação oferece o campo fértil ideal para a cultura da reflexão como marca da ação pedagógica.

A pesquisa-ação, segundo Franco (2012), abre espaço para apropriação por todos os envolvidos no processo, tanto das teorias expressas trabalhadas pelo grupo, como das práticas e metodologias utilizadas, o que possibilita a construção de concepções e transformações em suas práticas. Dessa forma, ela dialoga com a educação ambiental de tal maneira que as alterações nas atividades humanas, vinculadas a esse fazer educativo e investigativo, implicam em mudanças individuais e coletivas.

Para Loureiro (2006), esse fazer educativo se estabelece na busca de autonomia e liberdade humana, politização e problematização ambiental em sua complexidade, participação e exercício da cidadania, ruptura e transformação dos valores e práticas sociais. $E$, esse fazer educativo, encontra no campo da pesquisa-ação abertura epistemológica e metodológica suficiente para efetivação dessa práxis social.

A pesquisa-ação, considerada como uma estratégia metodológica de pesquisa social, onde existe uma interação ampla entre todas as pessoas envolvidas e o próprio pesquisador, através da qual surgem as descobertas dos problemas a serem investigados, não se limita apenas a ação de conscientização dos participantes da pesquisa, mas trabalha no intuito de produzir e aumentar o conhecimento de todas as pessoas envolvidas no processo (RICHARDSON, 2003).

Esta, quando comprometida com a transformação e tomada de consciência dos problemas e de suas origens que envolvem a sociedade, cria ambientes propícios para a realização de uma educação ambiental imbuída em um meio reflexivo, crítico e autocrítico, contínuo, pelo qual podemos romper com as barbáries dos padrões vigente de sociedade e de civilização, contribuindo para a efetivação dessa práxis social (LOUREIRO, 2006). 
Essa abertura epistemológica da pesquisa-ação, enquanto metodologia de pesquisa social e de ação para transformação, permite à educação ambiental atuar na reflexão dos conflitos socioambientais existentes e no embate das ideias que estão por trás destes conflitos, assumindo seu caráter não neutro, de forma contra hegemônica.

Dessa forma, a pesquisa-ação, enquanto ação para resolução de problema, onde pesquisadores e participantes estão envolvidos no processo e estes pretendem desempenhar um papel ativo na própria realidade (THIOLLENT, 2011), tende a caracterizarse, na educação ambiental, como processo educativo reflexivo, que problematiza para a compreensão e a ação de forma onilateral. Superando assim a separação entre conhecimento e ação, na busca de realização da prática de conhecer para e pelo atuar.

Nesse sentido, é de especial importância que a dialogicidade seja uma prática constitutiva do processo de investigação, através da vivência e discussões dos problemas pesquisados, da imersão do investigador na realidade dos participantes, da tomada de consciência por parte dos participantes desses problemas e das relações determinantes que os produzem.

Esse processo de investigação, baseado na ação e no diálogo, que problematiza as relações existentes na humanidade e entre esta e o meio ambiente, expondo a exploração, dominação e injustiça existentes nas relações socioambientais, se transforma em um processo de conscientização.

Isso garante à pesquisa-ação em educação ambiental condições efetivas para transformação não só dos participantes da pesquisa, mas também social, uma vez que estabelece novas formas de conceber o meio ambiente e de ações entre os indivíduos, e dos indivíduos com a natureza.

A pesquisa-ação, assim, pode cooperar para uma educação ambiental que implique mudanças individuais e coletivas, onde, como afirma Loureiro (2006), a dimensão política da educação seja para uma transformação societária, com atitudes individuais e ações coletivas condizentes com a emancipação, em que a dialética da vida encontre suas brechas dentro do contraditório para um movimento de transformação do mundo.

Um movimento que reinsira a humanidade na natureza, tão distanciada através do pensamento cartesiano, de forma que se perceba humanamente natural ou naturalmente 
humana. Reconhecendo a máxima defendida por Morin (2015) de que o todo está nas partes e as partes estão no todo.

\section{A complexidade e a dialética na pesquisa-ação em educação ambiental}

Como características fundamentais da pesquisa-ação em educação ambiental, vimos que é necessária a participação de todas as pessoas implicadas no processo investigativo e nos problemas investigados e, além disso, uma ação destinada a resolver os problemas em questão ou, ao menos, evidenciá-los a todos os envolvidos de modo que percebam a totalidade concreta da realidade em que estão inseridos.

A investigação do fenômeno através da complexidade e da dialética na pesquisa-ação em educação ambiental deve ser vista à luz das principais estruturas e tendências da formação social no qual a mesma está inserida. Dentro dessa visão totalizante e concreta da realidade, a formação social só poderá ser concebida como o conjunto das relações existentes na humanidade, entre a humanidade e a natureza, em desenvolvimento, no devir, produzida historicamente pela relação da humanidade através do trabalho e da práxis, na compreensão da complexidade da totalidade.

Isso requer, segundo Richardson, "Considerar o fenômeno social como algo determinado pela totalidade. Os fenômenos sociais são objetivos, independentes da vontade de indivíduos ou grupos isolados. Considerar o fenômeno social como algo determinado pelas classes sociais e estruturais" (2003, p. 190).

Nesse sentido, fazer pesquisa-ação em educação ambiental à luz da complexidade e da dialética, exige ter definidos e claros todos os pressupostos epistemológicos, gnosiológicos e ontológicos da pesquisa. Estes, devem estar voltados à descoberta da essência dos fenômenos e das leis que os regem, com a finalidade de evidenciar a relação existente entre as práticas sociais e suas relações com o trabalho, como estas são causadoras e, ao mesmo tempo, efeitos, em uma relação de recursão organizacional, das relações entre a humanidade e da humanidade com a natureza.

Entender o trabalho como uma categoria presente a ser discutida na pesquisa-ação em educação ambiental é compreender que a mudança ambiental extrapola a mudança 
cultural e comportamental, indo ao encontro de uma mudança social. Esta, está indiscutivelmente atrelada às práticas advindas das relações dos modos de produção e consumo dos seres humanos.

Layrargues (2011) aponta que é esse diálogo entre a cultura e o trabalho dentro dos planos material e simbólico que compõem os determinantes da crise ambiental, e ainda afirma que considerar a categoria trabalho como elemento constitutivo das relações dentro da humanidade e da humanidade com a natureza possibilita uma ação educativa que integre essa base da crise ambiental. Nessa perspectiva, o autor afirma:

É a consideração da categoria trabalho que fornece a concretude necessária para
que seja possível visualizar que os humanos não são seres vivos genéricos e
abstratos para serem qualificados linearmente numa relação humano-natureza
como é tão frequentemente posta, mas sim preenchidos de valores, interesse,
intencionalidades e intervenções físicas no mundo bastante diferenciadas.
(LAYRARGUES, 2011, p. 80)

O pensamento complexo e a dialética na pesquisa-ação em educação refletem ainda em uma pedagogia do contraditório, baseada no princípio da incerteza, que enfatiza a educação enquanto processo permanente, onde a reflexão não se exime da ação, transformando as concepções e as ações dos sujeitos.

O enfrentamento das incertezas que se estabelecem no campo da ação, requer levar em conta a complexidade que a própria ação já supõe, do acaso, do aleatório, das iniciativas tomadas em um processo de investigação onde todos os participantes decidem e constroem juntos. E ainda de como todo esse processo se desenvolve em um ambiente maior, em relação com outros contextos de outras complexidades, em sua totalidade, o que Morin (2011) vem a chamar de ecologia da ação.

Para esse enfrentamento, é necessário um racionalismo que supere não somente o pensamento cartesiano de isolamento das partes de sua totalidade, mas que reconheça as subjetividades presentes em todo o fenômeno investigado. Em um enfrentamento dos erros e das ilusões que possam levar às cegueiras do conhecimento (MORIN, 2011).

Loureiro (2006) alerta para interdependência existente entre as partes do real através da dialética, em um devir, em transformação permanente, o que dialoga com a máxima de Morin (2015) sobre a relação recursal de que o todo está nas partes e as partes 
estão no todo. Esse movimento, dentro da pesquisa-ação, que compreende que o real é contraditório e as verdades são provisórias, é primaz para transformação das concepções e ações.

Para Grabuska e Bastos (2003) a pesquisa pensada dessa forma, levando em conta as determinações históricas e os condicionantes sociais, estará constituindo uma concepção de investigação que se propõe a gerar emancipação. Planejada e executada nessa racionalidade emancipatória, a pesquisa-ação em educação ambiental pode auxiliar os seres humanos a interpretar a realidade a partir da compreensão das relações já citadas e de suas próprias práticas, concepções e valores, chegando assim à finalidade tanto da pesquisa-ação, quanto da educação ambiental, que vem a ser a transformação social.

Esse processo de emancipação e de transformação que se estabelece dialeticamente na individualidade e na coletividade, acontece, na pesquisa-ação em educação ambiental, não somente enquanto sujeito que toma consciência dos problemas socioambientais, mas também enquanto sujeito que produz conhecimento sobre esses problemas e as transformações necessárias.

Os participantes desse tipo de pesquisa, que são conduzidos à produção do conhecimento, se tornam também os sujeitos dessa produção, o que faz com que todo o processo de pesquisa se torne um instrumento de resistência e transformação, estabelecido a partir de uma ação educativa (LOUREIRO, 2006).

A visão que a pesquisa-ação em educação ambiental tem, amparada na complexidade e na dialética, para além da transformação, está direcionada à emancipação de todos os participantes da pesquisa, onde a humanidade compõe uma unidade dialética com a natureza e os sujeitos são pensados concretamente, e não abstratamente, em sua totalidade, através da práxis estabelecida nas relações advindas do trabalho e da cultura.

Isso acarreta a compreensão de que somos seres não somente biológicos, integrados e integrantes da natureza, mas também sociais, culturais e econômicos. Nos definindo, portanto, como multidimensionais e complexos. Nesse sentido, a criação de uma consciência socioambiental não pode subsistir a uma consciência política.

É exatamente essa abertura epistemológica da pesquisa-ação, de não neutralidade da ciência, que vai validar uma ação educativo-ambiental capaz de traduzir o apelo de ações 
individuais sem suplantar ações coletivas. Layrargues (2011) adverte que os educadores ambientais necessitam romper com a violência simbólica das ideologias hegemônicas, que sobrepõem a dimensão ética sobre a política e os valores sobre os interesses.

Para efetivação dessa compreensão da totalidade é preciso haver uma quebra paradigmática de ciência e de pensamento cartesiano. É preciso um pensamento complexo (MORIN, 2015), capaz de promover a superação dos dualismos e reducionismos que operam na compreensão do meio ambiente e da educação ambiental de forma comportamental, ou de disjunção do ser humano da natureza, ou simplesmente da redução da humanidade enquanto natureza, mas compreender o caráter multidimensional dos seres humanos enquanto seres biológicos, sociais, culturais, psicológicos e políticos.

Nesse sentido, a ação que se desenvolve dentro da pesquisa, enquanto instrumento de transformação, deve buscar superar a visão de mundo de disjunção, que fragmenta o olhar e a compreensão sobre a realidade. Ou como bem coloca Guimarães, uma "visão que separa as partes do todo focando na parte, numa perspectiva individualista e privatista e que cultiva uma postura desintegrativa e dicotômica que simplifica e reduz a complexidade da realidade" (2011, p. 16).

Loureiro (2011), adverte que essa fragmentação do saber e do conhecimento está intimamente atrelada à divisão social do trabalho, à expropriação dos direitos dos indivíduos de conhecerem a integridade do processo de produção e criação no qual estão inseridos, o que remete novamente a categoria trabalho e seus desdobramentos nas relações sociais e materiais da crise ambiental. Dessa forma, estando intrinsecamente relacionada à forma de sociedade moderna determinada historicamente.

Compreender, assim, a realidade concreta como unidade no diverso e síntese das muitas determinações históricas dentro da pesquisa-ação em educação ambiental, requer "partir do que é mais abstrato ou imediato e percorrer o processo contraditório de sua constituição real e atingir o concreto como um sistema de mediações e de relações cada vez mais complexas e que nunca estão dadas à observação" (CHAUÍ, 2012, p. 56).

Assim, a pesquisa-ação em educação ambiental, como ação educativa e investigativa, e ainda de produção de conhecimento através da práxis, permite reflexões sobre a totalidade da relação entre a humanidade e a natureza e entre os seres humanos. Ela se 
estrutura articulando a natureza, a história, o trabalho, o conhecimento, as práticas sociais, superando uma visão reducionista, fragmentada e a-histórica do concreto real.

\section{Da Totalidade na Pesquisa-Ação em Educação Ambiental}

A educação ambiental inspirada no diálogo, através da pesquisa-ação, torna-se instrumento de fortalecimento dos sujeitos, de emancipação destes, na compreensão do mundo em sua complexidade e das relações existentes na totalidade.

Essa totalidade, dentro da educação ambiental, compreende as relações do ser humano com a natureza e as relações de apropriação dos recursos naturais, culturais e humanos pelo capitalismo, através dos modos de produção e consumo estabelecidas pelo trabalho e relativas às relações sociais advindas desse processo.

Ou como afirma Lowy (1975), o ser humano, enquanto ser social, não pode ser separado da estrutura da totalidade e das organizações societárias, uma vez que o trabalho, a produção e a apropriação da natureza são responsáveis por sua própria antropogênese. Dessa forma, a própria consciência do homem, objeto de interesse da educação ambiental enquanto ferramenta para a transformação da sociedade, é já de antemão um produto social, pois não se estabelece especificamente pela individualidade, mas em conexão com toda a sociedade.

Pensar essa totalidade dentro da pesquisa-ação em educação ambiental é compreendê-la como um todo estruturado, ou:

[...] um sistema organizado por relações e fluxos, que em sua dinâmica, dão o sentido de permanência (organização e nexos lógicos) e de desordem (movimento de construção contínuo e indissociável entre todo e partes, sendo que cada parte é uma totalidade inserida em outras (totalidades). Significa racionalmente compreender que o singular ganha sentido em suas relações (totalizações) e que o todo é mais que a soma das singularidades, num movimento de mútua constituição (LOUREIRO, 2011, P. 147-148).

Essa compreensão da totalidade, onde o todo é maior que a soma das suas partes, também pode ser observada no pensamento de Morin (2015), cujo qual ainda defende que, ao mesmo tempo, o todo é menor que a soma das suas partes, pois nem todas as informações ou qualidades das partes estão expressas no todo. 
Essa totalidade não se caracteriza de forma harmoniosa, mas é necessariamente antagônica e dissonante numa dialética entre sociedade e natureza que se encontram através da práxis histórica, determinada pelas relações de trabalho e de cultura, cuja unidade, estabelecida na diversidade, não pode ser confundida com a diluição de uma dimensão na outra.

Portanto, a totalidade que a pesquisa-ação em educação ambiental deve investigar, está na realidade concreta, sendo possível ao pesquisador reproduzi-la idealmente. Como nos afirma Hungaro (2014), não se trata de conhecer os vários fatores, ou partes, ou aspectos que compõem a realidade e depois somá-los, mas, de entender a relação da unidade na diversidade presente, e que esta realidade é em si a totalidade.

Ou ainda como aponta Masson (2014), implica, dentro da pesquisa, investigar a realidade como um complexo que só pode ser compreendida se estiver atrelada em todas as suas relações com outros complexos, que juntos, formam a totalidade.

Assim, pesquisar a educação ambiental dentro de uma ação planejada, não significa encontrar os saberes, dimensões, percepções, ou concepções de forma autônoma e separada. Mas compreender a estrutura teórica, prática, de ideologias e categorias presentes no fenômeno, articuladas sob a perspectiva da realidade concreta, da totalidade.

Quanto a isso, Lowy (1975) adverte que o isolamento, a separação e a oposição abstrata das diferenças existentes na realidade são dissolvidas dentro da totalidade. Morin (2018) também apresenta que essa inadequação de fragmentação se torna invisível na complexidade, dentro das interações e retroações entre as partes e o todo.

\section{Da Práxis na Pesquisa-Ação em Educação Ambiental}

Enquanto categoria presente na pesquisa-ação em educação ambiental, a práxis se estabelece como uma atividade concreta, não espontânea ou instrumental, mas onde os participantes da pesquisa, através da reflexão e da ação, se afirmam no mundo, conhecendo e reconhecendo os problemas existentes em suas realidades e sendo modificados por essa reflexão e essa ação, na relação da teoria com a prática (KONDER, 1992). 
Loureiro adverte que, na educação ambiental, enquanto processo educativo, essa práxis seja de problematização, indo muito além da aquisição de informações, da sensibilização, da mudança de comportamento, "como se o correto fosse uma condição exclusivamente objetiva e de acesso à informação cientificamente produzida" (LOUREIRO, 2011, p. 132).

Dessa forma, enquanto pressuposto da investigação, a práxis implica ação e reflexão dos indivíduos envolvidos em todo processo, e ainda sobre o mundo que antecede e se materializa nas suas palavras e consciências, para poder transformá-los, como bem coloca Freire (1980).

Essa reflexão implica compreender a ideologia como uma forma de práxis social e como ela se estabelece nas relações sociais, uma vez que, como afirma Chauí (2012), ela parte da experiência imediata dos dados da vida social, construindo abstratamente um sistema de ideias e representações sobre a realidade, ocultando assim os processos que precisam ser revelados e superados para que se efetivem as transformações.

Implica entender, assim, que o processo de emancipação humana está atrelado a superação da alienação causada pelas ideologias, através da tomada de consciência. Para isso, como nos aponta Lowy (1975), essa práxis precisa ser revolucionária, ao mesmo tempo causa e efeito de um processo histórico onde a própria humanidade faz a sua história, e a mudança das circunstâncias coincide com a mudança (subjetiva) da humanidade.

A pesquisa-ação em educação ambiental se torna assim uma práxis educativa que é cultural e sensibilizadora, mas também fundamentalmente política, formativa e emancipadora, capaz de produzir transformação nos problemas socioambientais existentes, através de um movimento de libertação consciente e de superação das formas de alienação simbólicas, estruturais, individuais e coletivas. Ou, como bem coloca Guimarães:

[...] prática de transformação desta realidade a partir da construção de uma nova percepção que se reflete em uma prática diferenciada - teoria e prática, ação e reflexão na práxis dialógica da diversidade na unidade e da unidade na diversidade. Práxis que se realiza no coletivo e pelo coletivo (GUIMARÃES, 2011, p. 26-27).

Dessa forma, a pesquisa-ação em educação ambiental, enquanto práxis educativa para a transformação, vai fornecer, conforme salienta Loureiro (2006), as condições para 
uma ação modificadora simultânea entre os indivíduos e na sociedade, trabalhando a partir de suas realidades e visando a superação dos problemas socioambientais existentes, assumindo um papel fundamental, imprescindível, tanto objetivamente quanto subjetivamente.

\section{Considerações finais}

Pensar a pesquisa-ação em educação ambiental pautada em fundamentos teóricos, epistemológicos e metodológicos na Teoria da Complexidade e na Dialética é assumir, assim, o caráter de não neutralidade e da subjetividade presentes na ciência, na produção de conhecimento e nos processos educativos, já expressos tanto na educação ambiental, quanto na pesquisa-ação, enquanto modelo de pesquisa social alternativa.

A intencionalidade expressa nesse tipo de pesquisa mostra-se como essência para transformação social da qual se objetiva. Os participantes de todo o processo investigativo e educativo não se perfazem enquanto meros observadores do fenômeno, desvendando a realidade. Mas correspondem a seres políticos que se comprometem com a ciência, com a produção de conhecimento, com a sociedade, e contribuem com mudanças que começam dentro do próprio grupo.

Esse tipo de pesquisa desponta, para educadores e pesquisadores, como via alternativa para emancipação de todos os participantes envolvidos no processo de investigação e de educação, comprometidos na busca de sociedades ecologicamente equilibradas e socialmente justas, dentro da compreensão de que existe uma relação recursal entre estas duas.

Para que esse processo seja estabelecido, mostra-se primaz uma prática educativa de superação dos dualismos, reducionismos e isolamentos entre a cultura, a natureza e a humanidade. Isso requer o reconhecimento de categorias que estão presentes em todas as práticas sociais, inclusive na educação e na ciência. As relações advindas do trabalho e de suas implicações nos modos de produção e consumo na sociedade. A totalidade expressa nos fenômenos, captada através do movimento das consciências dos participantes, o que 
reflete a realidade concreta. E a práxis, enquanto ferramenta essencial para construção de emancipação e transformações na sociedade, na relação da teoria com a prática.

A pesquisa-ação em educação ambiental, sob a ótica da complexidade e da dialética, se mostra como uma alternativa de emancipação dos participantes envolvidos no fenômeno, no sentido da compreensão das ideologias presentes nos discursos educacionais e ambientais, de sua superação, e da construção de uma sociedade ambientalmente consciente.

\section{Referências}

CHAUÍ, Marilene. O que é ideologia. São Paulo: Brasiliense, 2012.

FRANCO, Maria Amélia Santoro. Pesquisa-ação e prática docente: articulações possíveis. IN_ Pesquisa em educação: possibilidades investigativas, formativas da pesquisa-ação, volume 1 / Selma Garrido Pimenta, Maria Amélia Santoro Franco, (orgs.). 2. ed. São Paulo: Edições Loyola, 2012.

FREIRE, Paulo. Conscientização - teoria e prática da liberdade: uma introdução ao pensamento de Paulo Freire. 3. ed. São Paulo: Moraes, 1980.

GRABUSKA, Claiton José; BASTOS, Fábio da Purificação de. Investigação-ação educacional: possibilidades críticas e emancipatórias na prática educativa. IN_Pesquisa-ação: princípios e métodos / Roberto Jarry Richardson (org.). João Pessoa: Editora Universitária/UFPB, 2003.

GUIMARÃES, Mauro. Armadilha paradigmática na educação ambiental. IN_Pensamento complexo, dialética e educação ambiental. CASTRO, Ronaldo Souza de; LOUREIRO, Carlos Frederico Bernardo; LAYRARGUES, Philippe Pomier (Orgs.). 2.ed. São Paulo: Cortez, 2011.

HUNGARO, Edson Marcelo. A questão do método na constituição da teoria social de Marx. IN_O método dialético na pesquisa em educação/organizadores Célio da Cunha, José Vieira de Sousa, Maria Abádia da Silva. Campinas, SP: Faculdade de Educação, Universidade de Brasília, UnB, 2014.

KONDER, Leandro. O futuro da filosofia da práxis. 2. ed. Rio de Janeiro: Paz \& Terra, 1992.

LEFF, Enrique. Ecologia, capital e cultura: a territorialização da racionalidade ambiental. Petrópolis, RJ: Vozes, 2009. 
LAYRARGUES, Philippe Pomier. Muito além da natureza: educação ambiental e reprodução social. IN_Pensamento complexo, dialética e educação ambiental. CASTRO, Ronaldo Souza de; LOUREIRO, Carlos Frederico Bernardo; LAYRARGUES, Philippe Pomier (Orgs.). 2.ed. São Paulo: Cortez, 2011.

LOUREIRO. Carlos Frederico Bernardo. Complexidade e dialética: contribuições à práxis política e emancipatória em educação ambiental. IN_Educação e Sociedade. Campinas, vol. 27, n. 94, p. 131-152, jan/abr. 2006.

LOUREIRO, Carlos Frederico Bernardo. Problematizando conceitos: contribuição à práxis em educação ambiental. IN_Pensamento complexo, dialética e educação ambiental. CASTRO, Ronaldo Souza de; LOUREIRO, Carlos Frederico Bernardo; LAYRARGUES, Philippe Pomier (Orgs.). 2.ed. São Paulo: Cortez, 2011.

LOWY, Michael. Método dialético e teoria política. Tradução de Reginaldo Di Piero. Rio de Janeiro: Paz e Terra, 1975.

MASSON, Gisele. A importância dos fundamentos ontológicos nas pesquisas sobre políticas educacionais: contribuições do materialismo histórico-dialético. IN_O método dialético na pesquisa em educação/organizadores Célio da Cunha, José Vieira de Sousa, Maria Abádia da Silva. Campinas, SP: Faculdade de Educação, Universidade de Brasília, UnB, 2014.

MORIN, Edgar. Introdução ao pensamento complexo. 5 ed. Porto Alegre: Sulina, 2015.

MORIN, Edgar. Os sete saberes necessários à educação do futuro. 2 ed. rev. São Paulo: Cortez; Brasília, DF: UNESCO, 2011.

PIMENTA, Selma Garrido. Introdução. IN_Pesquisa em educação: possibilidades investigativas, formativas da pesquisa-ação, volume 1 / Selma Garrido Pimenta, Maria Amélia Santoro Franco, (orgs.). 2. ed. São Paulo: Edições Loyola, 2012.

REIGOTA, Marcos. O que é educação ambiental. 2. ed. São Paulo: Brasiliense, 2014.

RICHARDSON, Roberto Jarry. Como fazer pesquisa-ação? IN_Pesquisa-ação: princípios e métodos / Roberto Jarry Richardson (org.). João Pessoa: Editora Universitária/UFPB, 2003.

THIOLLENT, Michel. Metodologia da pesquisa-ação. 18. ed. São Paulo: Cortez, 2011. 
Submetido em: 15-10-2020.

Publicado em: 23-04-2021.

Revista Eletrônica do Mestrado em Educação Ambiental Programa de Pós-Graduação em Educação Ambiental - FURG v. 38, n. 1, p.95-112, jan./abr. 2021. E-ISSN: 1517-1256 